\title{
Los factores posibilitadores y las expresiones de la violencia en los noventa1
}

\author{
José Miguel Cruz
}

\section{Resumen}

La violencia que vive El Salvador en la actualidad no surge de la nada. Este país centroamericano ha reunido en la posguerra toda una serie de condiciones que han posibilitado la exacerbación de la agresividad institucionalizada. A pesar de que la historia salvadoreña muestra que la violencia ha estado siempre presente en diversas modalidades, el prolongado conflicto bélico acrecentó la ya existente cultura de violencia; además en la era de la paz, el país ha tenido que lidiar con unos aparatos de justicia y seguridad principiantes y no del todo eficientes; finalmente, la ingente cantidad de armamento ha contribuido también al descontrol de los índices delincuenciales. Este artículo desarrolla además algunas caracterizaciones de la violencia criminal en la actualidad.

\section{El contexto de violencia en EI Salvador}

Para comprender la epidemia de violencia en El Salvador es necesario situar al país en un contexto histórico. Pero no se trata de hacer un reco- rrido histórico señalando fechas y acontecimientos, se trata más bien de colocar a El Salvador en la dimensión histórica que lo diferencia del resto de países de la región y que, al mismo tiempo,

1. Este artículo constituye un resumen del tercer capítulo del informe de investigación "La violencia en El Salvador en los noventa", el cual ha sido realizado por el Instituto Universitario de Opinión Pública (IUDOP) con la colaboración del Centro de Infromación, Documentación y Apoyo a la Investigación (CIDAI), ambos de la Universidad Centroamericana (UCA) bajo los auspicios del Banco Interamericano de Desarrollo (BID) dentro del Proyecto de Red Regional de Centros de Investigación. 
junto con la magnitud del problema, lo convierte en un caso muy particular.

La violencia no es un fenómeno reciente en la sociedad salvadoreña. Durante décadas, los ciudadanos del país más pequeño de Centroamérica han vivido con la violencia en distintas modalidades pero cuya característica común ha sido siempre la enorme magnitud del fenómeno. No se tienen cifras, pero diversos autores (Alvarenga, 1996; White, 1970) han señalado la significativa dimensión del fenómeno a comienzos de siglo y cuya expresión más conocida es la llamada "Matanza de 1932" (ver Anderson, 1976). Con todo, se puede decir que la violencia actual que enfrentan los salvadoreños forma parte de un prolongado ciclo en el cual la llamada "violencia delincuencial" es la más nueva particularidad de una forma de agresión social, cuyas expresiones anteriores más evidentes tuvieron por mucho tiempo un semblante social —expresado en los continuos levantamientos de indígenas y campesinos (Cardenal, 1996)-, que luego en el transcurso del siglo se transformó en violencia política - al institucionalizarse por parte del Estado-, para luego, en el decenio de

doce años de guerra crearon
una cultura de violencia para la que los
acuerdos no fueron diseñados.
los ochenta, convertirse en una escalada de guerra civil abierta. En otras palabras, El Salvador estaría enfrentando un nuevo período dentro de una perniciosa y continua escalada de violencia. Por ello, es muy importante subrayar la particularidad del contexto salvadoreño para entender esta nueva y, según algunas cifras, más aguda expresión de la violencia.

\subsection{El conflicto armado salvadoreño}

En el presente, la nación salvadoreña se encuentra bajo las secuelas de una prolongada guerra civil que, como tal, duró alrededor de doce años. Algunos cálculos conservadores atribuyen a este conflicto salvadoreño un costo en vidas humanas que asciende a las 75,000 personas en ese lapso de tiempo. Si se hace un ejercicio de tasación con estos datns dividiendo la cantidad de muertos en la guerra por el número de años que duró el conflicto, se tiene un saldo de alrededor de 6,250 personas muertas anualmente por causa de la guerra. Este dato, sobre la base de una población total nacional promedio de 5 millones de personas ${ }^{2}$, arrojaría una tasa de homicidios para esas fechas de aproximadamente los 125/100,000 habitantes (ver IUDOP, 1996). De hecho, los indicadores de mortalidad publicados por la Organización Panamericana de la Salud (OPS) y basados sobre datos del año 1990 en El Salvador, reportan una tasa de mortalidad ajustada por edad por causas externas de 282/100,000 en el género masculino. Los mismos indicadores muestran que para el mismo año, las muertes por homicidio representan el 43 por ciento de todas las causas externas de muerte (ver Organización Panamericana de la Salud, 1994). Lo anterior ofrece una idea de la dimensión del conflicto armado salvadoreño.

Es a la luz de este ciclo histórico y, sobre todo. del conflicto bélico bajo el cual hay que analizar el caso salvadoreño, que lo hacen diferente del resto de países que enfrentan las epidemias de violencia. Existen tres elementos esenciales en la particularidad salvadoreña y que están relacionados directamente con la guerra. El primero se relaciona con la magnitud percibida del conflicto; en segundo lugar, se encuentra la duración del conflicto; $y$, finalmente, hay que tomar en cuenta el exitoso y abrupto final de la confrontación.

A diferencia de otros países con conflagraciones similares o con guerrillas itinerantes, el conflicto salvadoreño llegó a ser considerado abiertamente como una guerra civil ${ }^{3}$, esto convirtio a la contienda bélica en un fenómeno a gran escala. Es más, por la particular visión de la época, el conflicto salvadoreño que tenía causas y dinamismos endógenos, terminó siendo parte también del marco de confrontación de la guerra fría. La guerra salvadoreña se convirtió en un evento totalizante

2. Esto según las proyecciones del Ministerio de Planificación publicadas en los Indicadores Sociales y Económicos arrojados por la Encuesta de Hogares de Propósitos Múltiples en 1990.

3. Sobre todo a partir de la Declaración Franco-Mexicana en 1982 que reconocía al FMLN (la guerrilla izquierdista) el estatus de fuerza beligerante en el conflicto. 
en el orden social del país (Martín-Baró, 1988). Este proceso totalizador fue favorecido por los esfuerzos de las partes por imponerse en la contienda, por las campañas que buscaban atraer hacia sí el apoyo, al menos pasivo, de la población y por la reducida extensión geográfica del territorio salvadoreño. Por consiguiente, la vida nacional estaba en función del conflicto: en mayor o menor medida, la guerra impactó a toda la población. En segundo lugar, la guerra en El Salvador no sólo fue intensa, fue también prolongada. Esto provocó que cl reordenamiento social impuesto por la guerra dejara de ser transitorio para institucionalizarse y crear normas de convivencia que durarían por mucho tiempo. Y no sólo eso, la persistencia de la guerra provocó que generaciones de ciudadanos crecieran y se formasen bajo una sociedad militarizada y conflictuada consigo misına. Miles de niños y jóvenes de desarrollaron en un entorno decisivamente marcado por la violencia en el que muchos de ellos participaron directamente. Finalmente, quizás una de las particularidades más obvias del caso salvadoreño es el logro exitoso de la lucha armada. A diferencia de otros países con conflictos parecidos donde los tratados de paz sólo han mitigado parcialmente los conflictos o en los que persisten grupos armados que continúan confrontando al Estado, en El Salvador los acuerdos de paz significaron el fin definitivo e inesperado de la prolongada guerra; esto implicó que, a pesar de la gravedad y la duración de la lucha armada, ésta terminara prácticamente de la noche a la mañana, sin los graves problemas de persistencia de conflictos regionales 4 .

El proceso que llevó a la firma de los acuerdos de paz no fue un hecho repentino; más bien, fue un proceso lento y difícil, pero el impacto de los tratados en acallar las armas de la lucha política fue eficaz y, para muchos, inesperado. Sin embargo, doce años de guerra crearon una cultura de violencia para la que los acuerdos no fueron diseñados. La paz repentina creó una serie de desafíos y puso al descubierto una cantidad de problemas

para los cuales la sociedad parecía no haberse preparado. La guerra terminó, pero para muchos ciudadanos las causas de la misma seguían presentes (ver $E C A, 1994)$. Los salvadoreños experimentaron el fin de la guerra, pero al mismo tiempo comenzaron a percibir que la violencia no había sido erradicada de la sociedad. Rápidamente, la mayor parte de los ciudadanos empezó a acusar el elevado nivel de violencia delincuencial y comenzó a exigir respuestas eficientes por parte del Estado para detener la nueva ola (Instituto Universitario de Opinión Pública, 1993). Sin embargo, la violencia había cambiado de paradigma: ya no encajaba en el ejercicio metódico y planeado de las operaciones de gueта, con interlocutores claros y legitimados con quienes negociar; ahora, bajo condiciones renovadas de paz, la violencia se presentaba difusa y sin orden, diferente pero igualmente considerable.

\subsection{Las secuelas de la guerra $y$ el contexto posibilitador de la violencia}

La tesis principal de este apartado de la investigación es que el conflicto bélico dejó una serie de secuelas que crearon o estimularon las condiciones para la existencia de la violencia que en la actualidad vive El Salvador. De acuerdo con Ignacio Martín-Baró, uno de los constitutivos básicos de la violencia es el contexto social posibilitador, este contexto se forma de varios elementos. En primer lugar, por la llamada "cultura de la violen-

4. Aunque hacia finales de 1993 se dio un rebrote de la violencia por causas políticas que hizo peligrar el proceso, esto no desembocó en una espiral de violencia y, en general, la bandas armadas que subsistieron - muchas, remanentes de los antiguos escuadrones de la muerte paramilitares- se orientaron más a actividades delincuenciales que a la desestabilización política. 
cia" que se refiere a un "marco de valores y normas, formales e informales, que acepte la violencia como una forma de comportamiento posible e incluso la requiera" (1996, pág. 373). En segundo lugar, el contexto posibilitador incluye también el nivel de presencia y eficacia de los sistemas institucionales de control social, esto es, el sistema de justicia y el sistema judicial. Finalmente, como parte del contexto posibilitador están aquellos elementos situacionales que facilitan el uso de la violencia, por ejemplo, la disponibilidad y el acarreo de armamento y el consumo de drogas y alcohol. Estos mismos elementos se encuentran en el modelo teórico de los factores de riesgo propuesto por Guerrero (1997).

El desborde de la violencia posbélica no es casual. Tal y como se plantea la violencia en la actualidad, los elementos contextuales que han facilitado la instalación de la violencia fueron creados o exacerbados como producto del conflicto armado salvadoreño. La cultura de la violencia, la debilidad institucional de los sistemas policiales y de justicia y la disponibilidad de armamento constituyen secuelas de la guerra que se convirtieron en factores condicionantes del fenómeno contemporáneo. Esto no quiere decir que se atribuye totalmente la responsabilidad de la violencia actual al pasado conflicto bélico. Ciertamente, por ejemplo, no se quiere decir acá que la cultura de la violencia surgió en la guerra o que, de no haber sido por la contienda armada, no existiese el problema en la actualidad. Lo que se pretende explicar es que la guerra del decenio de los ochenta, con sus secuelas, tiene mucha relación con la forma en que se ha posibilitado, presentado y configurado la violencia no bélica de los años noventa.

\section{A. La cultura de la violencia}

Sin duda, la guerra tuvo varios efectos en la sociedad salvadoreña; sin embargo, uno de los efectos más ocultos o, mejor dicho, menos abordados, en la discusión de las secuelas tiene relación con el impacto psicosocial de la misma sobre la población. Las confrontaciones bélicas no sólo dejan pérdidas en vidas humanas y en recursos materiales en una sociedad, también dejan marcas en la población que, más temprano que tarde, comienzan a cobrar efecto. Una de esas huellas constituye la creación de sistemas de valores y normas sociales que legitiman y privilegian el uso de la violencia en cualquier ámbito por sobre otras formas de comportamiento social. Lo que se llama la cultura de la violencia. El conflicto armado exacerbó esa cultura existente y le dio un carácter casi universal. Si antes la violencia era permitida bajo ciertas circunstancias llamadas "especiales" o bajo regímenes de excepción, la guerra absolutizó esas condiciones e institucionalizó las normas que rigen tales situaciones.

Concretamente, la guerra civil militarizó la sociedad, deterioró la convivencia social y adiestró a los ciudadanos en el uso de la agresión como medio instrumental universal para dirimir las diferencias (Samayoa, 1986; Martín-Baró, 1990). Durante más de una década, los salvadoreños vivieron en una sociedad militarizada en la que la autoridad residía claramente en quienes portaban las armas. Con el deterioro de la convivencia social se trivializó el valor de la vida humana, sobre todo si ésta era la del adversario. Pero sobre todo, la guera mostró por largo tiempo a los ciudadanos las ventajas del uso de la violencia para lograr los propios propósitos; esto es aplicable no sólo a los combatientes durante la guerra sino también a buena parte de la población.

A pesar de que la letra de los acuerdos de paz buscaba rechazar lo anterior formalmente, estos elementos en su mayoría estaban ya sedimentados socialmente y asumidos como normas por lo prolongado de la experiencia. Mucho de lo anterior ha sobrevivido al conflicto. Algunas expresiones de la militarización persisten en la actualidad: la necesidad de la portación de armas, la exigencia de contar con los militares para resolver algunos problemas y la añoranza por el respeto a la autoridad son algunas expresiones. Según el estudio ACTIVA (IUDOP, 1996b), el 22 por ciento de los adultos del Area Metropolitana de San Salvador (AMSS) afirmó que le gustaría tener un arma de fuego para su protección. Otro estudio realizado por el Instituto Universitario de Opinión Pública (1996a) en los centros educativos del AMSS reve- 
Ii) que más del 18 por ciento de los jóvenes entre I 1 y 18 años de edad había acudido a clases en el Illimo mes con algún tipo de arma (armas blan''us, armas de fuego y artefactos explosivos). Por "Ir') lado, el mismo estudio ACTIVA (IUDOP, (1)(96) reveló que casi el 80 por ciento de los salvindoreños consultados piensa que la presencia mililur es necesaria para combatir la delincuencia en 'l país. Ello muestra la prerrogativa que aún se vicle dar a las opciones militares.

El mejor indicador de la trivialización de la vida humana en la posguerra como producto del deterioro de la convivencia social lo constituyen lus mismas cifras de los homicidios. De acuerdo iun los datos de muertes violentas registradas por Iı Fiscalía General de la República, en El Salvadur ocurrirían un promedio de 8,000 homicidios 'ntre intencionales y no intencionales. Esto signilica tasas de alrededor de 140 muertes por cada cien mil habitantes. Sin embargo, los estudios de Ictitudes y de opinión pueden ser útiles también para confirmar lo anterior: una encuesta de opinión pública realizada por el IUDOP en 1995 a nivel nacional mostró que el 45 por ciento de los consultados estaba de acuerdo con el accionar perpetrado por un grupo de limpieza social llamado la "Sombra Negra", el cual estaba asesinando pandilleros juveniles (maras); de hecho, el estudio ACTIVA (IUDOP, 1996b) reveló que de todas las ciudades participantes en la investigación, San Salvador tendría uno de los porcentajes inás altos de aprobación hacia los grupos de limpieza social. Los resultados del mismo estudio señalaron que dos de cada tres salvadoreños creen que la pena de muerte se justifica en ciertas ocasiones; de nuevo éste fue el porcentaje más elevado en comparación con el resto de ciudades participantes en el estudio. Con todo, los salvadoreños parecen muy dispuestos a aceptar muertes violentas como solución a determinadas problemáticas.

Pero probablemente, en el área de la cultura de la violencia, el impacto más decisivo de la conflagración bélica tiene relación con el proceso de aprendizaje de la misma. Bajo el entorno de la guerra crecieron varias generaciones de salvadoreños, la mayoría de ciudadanos aprehendió la violencia' como forma de vida: muchos de ellos nacieron y se formaron sin conocer lo que era una sociedad pacífica y muchos otros fueron educados directamente para la guerra y para el uso de la violencia. Por ejemplo, al final de la guerra muchos excombatientes que ingresaron a sus ejércitos cuando aún eran niños no estaban preparados para hacer otra cosa sino usar las armas. El fin del conflicto dejó a toda una población intentando reconstruir sus relaciones humanas y tratando de aprender formas para convivir y laborar en condiciones de paz. Muchas personas celebraron la paz alcanzada, pero personalmente no sabían cómo conducirse en ese nuevo entorno y siguieron comportándose de la misma manera que lo hicieron durante largo tiempo.

Los acuerdos de paz previeron en cierta forma la desmovilización de una gran cantidad de combatientes ${ }^{5} \mathrm{y}$, más por razones políticas que por razones técnicas, se diseñaron programas de reinserción a la vida civil de los mismos; sin embargo, en opinión de algunos expertos consultados por los responsables de este estudio, estos programas no tuvieron el impacto deseado en los antiguos efectivos porque estuvieron más enfocados en la capacitación técnica y en el ofrecimiento de tierra - los cuales no eran del mayor interés para

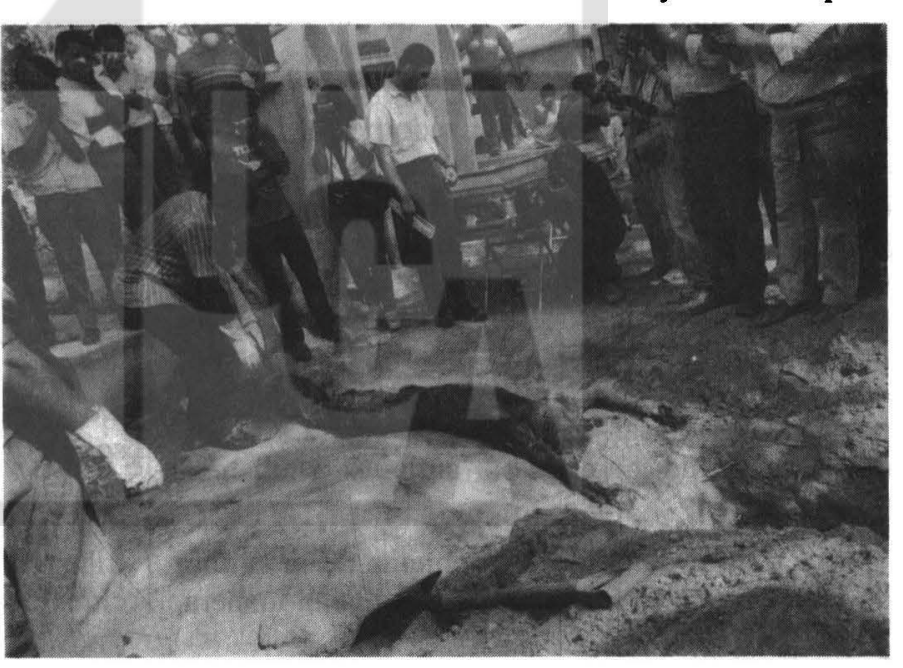

5. Se calcula que para finales de 1993 se habran desmovilizado alrededor de 46,000 efectivos, aproximadamente el 75 por ciento pertenecía a las Fuerzas Armadas y el 25 por ciento a la antigua guerrilla (ver Corado, 1994). 
los excombatientes - que en una eficaz reinserción a una vida laboral realmente productiva ${ }^{6}$, lo cual obligó a muchos a decantarse por una vida al margen de la ley haciendo uso de lo que habían aprendido durante la guerra. Esto puede verse en la modalidad criminal predominante en muchos delitos. Según la prensa nacional, las masacres constituyeron una de las modalidades frecuentes de actos criminales entre 1995 y 1996, éstas son ejecutadas bajo técnicas que recuerdan a operativos militares de exterminio (García, 1996). De hecho, según declaraciones de funcionarios policiales, la mayoría de estos delitos ha sido cometida por exmilitares y exguerrilleros que combatieron durante la guerra (Hernández, 1996).

Por otro lado, uno de los impactos más claramente expresados en la sociedad salvadoreña del aprendizaje del uso de la violencia se encuentra en la proliferación de pandillas o "maras" juveniles. De acuerdo con informes de la Policía Nacional Civil, en el AMSS existen alrededor de 20,000 jóvenes predominantemente entre 15 y 21 años que integran dichas pandillas. Todos los pandilleros en la aclualidad fueron niños que crecieron bajo la guerra. Una de las características primordiales de estos grupos de jóvenes es el uso frecuente de la violencia y el comportamiento delictivo. Según un sondeo realizado por el Instituto Universitario de Opinión Pública (1996c) entre este tipo de jóvenes, cerca del 70 por ciento de los jóvenes habría estado en prisión alguna vez y más de la mitad de los pandilleros habría estado hospitalizado por agresiones. En una entrevista con los investigadores, los mismos pandilleros afirman que muchas de sus técnicas para enfrentar a grupos rivales se basan en tácticas de guerra aprendidas o transmitidas a ellos por antiguos combatientes.

Por todo lo anterior, el problema de la cultura de violencia en El Salvador es, de alguna manera, un problema de salud psicosocial. La normativa de la violencia se ha sedimentado tanto en la sociedad salvadoreña que el comportamiento agresivo y violento es ya una respuesta institucionalizada. Muchas masacres ocurridas en los últimos tres años en las áreas rurales del país no parecen tener motivaciones delincuenciales (robo, violación, etc.), ni siquiera parecen estar motivadas políticamente - lo cual era usual hasta hace seis años-, más bien parecen estar motivadas por rencillas entre familias o personas $y$ son resueltas mediante el exterminio del enemigo o del rival. Esto es posibilitado en buena medida por la sensible deficiencia de cobertura de los aparatos de justicia y seguridad pública y por la ingente cantidad de armamento heredado del conflicto bélico.

\section{B. Las instituciones de justicia y seguridad}

Otro efecto del conflicto armado salvadoreño que ha tenido impacto en el desarrollo de la violencia en los noventa es la situación de las instituciones encargadas de proveer seguridad pública y justicia a la población. La guerra no sólo tuvo un impacto en la exacerbación de la cultura de violencia, también terminó de debilitar el poco operante sistema de justicia y desnaturalizó por completo las funciones de los cuerpos de seguridad. De acuerdo con un informe de la División de Derechos Humanos de la Misión de Observadores de las Naciones Unidas en El Salvador, fechado el 5 de junio de 1992, la debilidad del sistema penal salvadoreño se debía a "su propia estructura y a su pasado vinculado con el conflicto armado" (ver Naciones Unidas, 1995a, p. 263). De hecho, la guerra no sólo provocó que los recursos y el funcionamiento de la administración de justicia se orientaran significativamente a legitimar las operaciones bélicas del bando oficial contribuyendo al compromiso político y a la corrupción en la administración de justicia, sino que

6. Estos programas aparentemente tuvieron éxito al cumplir con los propósitos políticos de evitar grupos rearmados que desestabilizaran el pars, pues los excombatientes fueron puestos de inmediato en procesos de instrucción técnica y se les ofreció tierra para trabajar; pero posteriormente estos programas no encontraron la manera de colocar con éxito a los antiguos combatientes en el mundo laboral. 
también provocó que extensas áreas del país quedaran sin delegados de las instituciones judiciales? ${ }^{7}$. Esto causó que al final de la guerra, la restitución (o instalación) de las institucionalidad jurídica fuese un proceso lento y complicado. La administración de justicia no se instituyó rápidamente: amplias zonas del país se mantuvieron sin tribunales, sin oficinas de la Fiscalía o la Procuraduría de Derechos Humanos sino hasta tiempo después de lograda la paz. Además, la depuración del sistema judicial - proceso pactado en los acuerdos- ha sido prolongada y ha estado más sujeta a negociaciones políticas y a criterios administrativos que a la necesidad de erradicar la corrupción y restablecer el or-

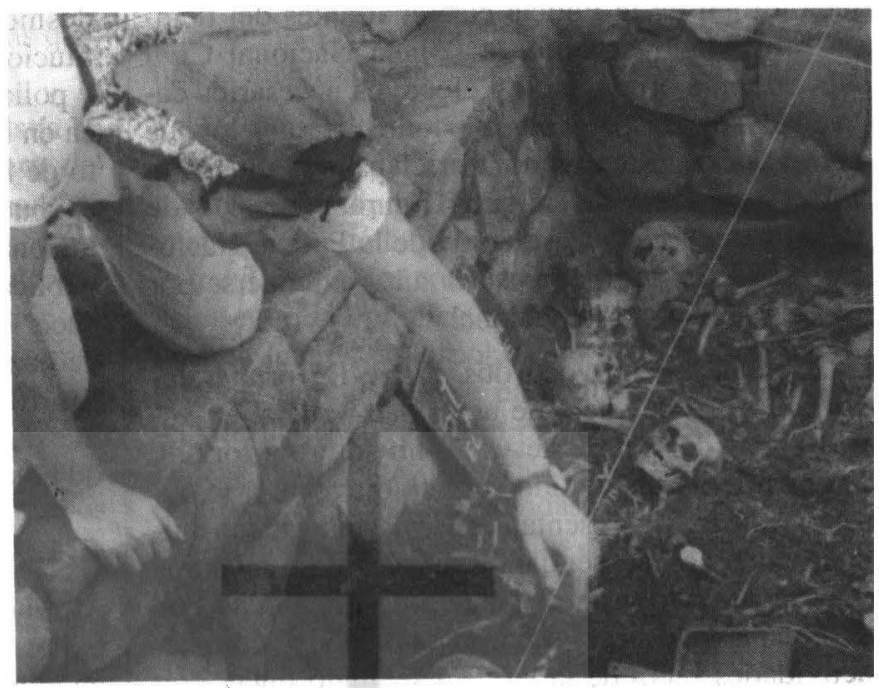
den jurídico (Spence et al, 1997; ver Popkin et al, 1994). Ello ha provocado que el sistema de justicia después de la guerra no sea lo suficientemente eficaz para enfrentar la ola de violencia y delincuencia posbélica. Por ejemplo, la encuesta sobre delincuencia llevada a cabo por el IUDOP en 1993 reveló que, según las víctimas, sólo el 26.5 por ciento de las denuncias interpuestas por algún delito fueron investigadas. Un reporte de la Dirección de Política Criminal del Ministerio de Justicia (1996) muestra que en los años 1993 y 1994, más del 80 por ciento de los reclusos en el sistema penitenciario nacional carecían de condena. Lo anterior produjo la percepción de un sistema de justicia poco operante que favoreció las condiciones para la impunidad, la sensación de inseguridad ciudadana y el aparecimiento de actiludes en contra del orden legal. Un estudio realizado por el Instituto Universitario de Opinión Pública (1996b) con Texas Christian University, reveló que alrededor del 40 por ciento de los salvadoreños cree que es mejor ignorar las leyes cuando no se está de acuerdo con ellas y para resolver los problemas rápidamente; es más, cerca del 46 por ciento afirmó que cuando el gobierno no lo hace "la gente tiene el derecho de tomar la justicia por su propia mano".

En el caso del sistema policial, la situación salvadoreña es particularmente especial. Hasta la fir-

ma de los acuerdos de paz existían al menos tres cuerpos con funciones de seguridad pública que estaban adscritos a las fuerzas armadas: 'la Policía Nacional, la Guardia Nacional y la Policía de Hacienda. En realidad, antes y durante la guerra especialmente en el último período--, estos cuerpos de autoridad estaban más orientados a la lucha en contra del enemigo ideológico del gobierno que a las funciones de seguridad pública; por tanto, en la década de los ochenta, la estructura y los recursos de los mismos estaban al servicio del conflicto bélico y no en función del control criminal, aunque también asumían tales tareas junto con el Ejército. Sin embargo, uno de los puntos esencialès de los acuerdos de paz que finalizó la guerra contemplaba, como parte de la depuración y reestructuración de la fuerzas armadas, la desaparición de los tres cuerpos de seguridad y la creación de una totalmente nueva Policía Nacional Civil (PNC), que ya no estaría bajo la responsabilidad de los militares sino de los civiles. Así, las instituciones Guardia Nacional y Policía de Hacienda fueron disueltas y sus miembros desmovilizados o integrados a las Fuerzas Amadas, mientras que la Policía Nacional entró a un lento proceso de desintegración que iba paralelo a una todavía más lenta constitución y despliegue de la PNC. Sin embargo, una serie de hechos precipitaron la diso-

7. ONUSAL informó que, durante la guerra, nueve de los catorce departamentos del país funcionaban con "jueces en el exilio", es decir, tribunales que tenían dificultades para ejercer su autoridad en las áreas conflictivas y, por lo tanto, lo hacían desde otros lugares (Naciones Unidas, 1995a). 
lución total de la Policía Nacional antes del tiempo proyectado ${ }^{8}$, cuando la Policía Nacional Civil aún no tenía el número de efectivos necesarios capacitados y desplegados en todo el país, lo que provocó que extensas zonas del país se quedaran sin el resguardo de ninguna figura policial o de autoridad. Desde la disolución de la Policía Nacional, a la PNC le tomó casi un año extenderse por el resto del territorio nacional.

Lo anterior provocó dos cosas. En primer lugar, un sensible vacío de autoridad policial en varias zonas del país; este vacío no sólo era formal, también tenía un sentido subjetivo: frente a la ausencia de los representantes de la autoridad, muchas personas se sentían desprotegidas, mientras que otras advirtieron el espacio de impunidad que se creaba y lo aprovecharon para poder cometer actividades fuera de la ley. En segundo lugar, con la abrupta transición, el naciente cuerpo policial tuvo que enfrentar una tarea para la cual no estaba lo suficientemente preparado y tampoco disponía de los recursos necesarios en un principio. De hecho, según un informe del Secretario General de la ONU sobre la Misión de Observadores en El Salvador, "los primeros graduados de la Policía Nacional Civil no estaban adecuadamente equipados y carecían de los me-

La exacerbación de la ya existente cultura de violencia, la fragilidad de los aparatos encargados de la justicia y la seguridad pública y la gran circulación de armas por la población han sido producto de la historia reciente de conflicto y paz sin previsión que ha enfrentado este país centroamericano. dios para cumplir sus funciones con eficacia", entre otros problemas (Naciones Unidas, 1997, p. 123). Así, el rol de seguridad pública de un país con muchas condiciones para la violencia tuvo que ser asumido por una institución inexperta. Algunos analistas, evaluando la situación de violencia en El Salvador, afirmaron que en tales circunstancias inclusive un cuerpo con mayor veteranía estaría en problemas (Spence y otros, 1997).

Así, en los primeros años después del fin de la guerra, El Salvador no poseía la capacidad institucional en el área de la seguridad pública como para hacer frente a la creciente delincuencia producto, en parte, del considerable número de desmovilizados desempleados. Además, la institucionalidad y capacidad de los sistemas judicial y policial se vio mermada por la dimensión política en la cual se tenía que mover el restablecimiento de la paz. Las negociaciones políticas limitaron en buena medida el apoyo y el desarrollo institucional de los aparatos vinculados a la seguridad pública y en ciertas ocasiones llegaron inclusive a hacer peligrar las metas propuestas en el tratado de paz. Ello significó que, además de cumplir con sus funciones, el sistema judicial tanto como la nueva policía estuvieran permanentemente lidiando con una compleja dinámica interna.

\section{La disponibilidad de armamento}

Más del 50 por ciento de las muertes por homicidios reportada por el Instituto de Medicina Legal en el área metropolitana de San Salvador ocurrió a causa de un arma de fuego o un artefacto explosivo. La guerra civil salvadoreña no sólo se encargó de armar a los dos ejércitos contendientes, sino que además distribuyó una ingente cantidad de armamento entre la población civil, en la búsqueda de apoyo por parte de cada bando. Sin embargo, este armamento no fue recogido en su totalidad al final del conflicto armado. Aunque el tratado de paz contemplaba la recolección total de armamento en manos de las antiguas fuerzas guerrilleras y de los civiles, los esfuerzos en este sentido no dieron los frutos esperados ya que los inventarios de armas presentados al fin de la guerra por las partes en conflicto no eran exactos (ver Naciones Unidas, 1995b). Muchos excombatientes prefirieron guardar y esconder el armamento que habían obtenido durante la conflagración. La mayor parte de los esfuerzos de recolección en este sentido fue ineficaz; un informe de Naciones Unidas detalla que casi un año después de la firma de los acuerdos, de manos civiles sólo se habían recogido 100 armas de un total calculado en varios miles (Naciones Unidas, 1995c). Con

8. El evento más conocido y determinante fue el violento asalto a un banco perpetrado por policías nacionales uniformados y el cual fue filmado y transmitido por un noticiero local de televisión. 
todo, nadie sabe a ciencia cierta cuántas armas quedaron desperdigadas después del conflicto.

Mucho de este armamento no sólo consistía en artefactos de pequeño calibre, buen número del mismo estaba formado por armas largas, de grueso calibre y explosivos. Parte de este armamento subsiste todavía en manos de civiles, lejos del alcance de las autoridades. En 1996, una organización civil inició una campaña de recolección de armas canjeádolas por bienes de consumo básico. La campaña ha sido exitosa pero insuficiente. Los organizadores tuvieron que suspenderla mucho antes de lo planeado porque se quedaron sin recursos para el canje, aunque han habido esfuerzos para continuarla. Entre el armamento recolectado de manos de civiles se encontraron hasta lanzacohetes y explosivos plásticos C-4, entre un elevado número de granadas y armas largas. De hecho, de los 2,467 decomisos de armas efectuados por la Policía Nacional Civil en 1995, el 21 por ciento lo constituían "armas de guerra".

De acuerdo con la Policía Nacional Civil, existen alrededor de 150,000 armas registradas en manos de civiles, sin embargo, las mismas autoridades calculan más de 120,000 armas que están en circulación y que no han sido registradas - muchas por ser "de uso privalivo de la Fuerza Armada". Según los resultados del estudio ACTIVA (IUDOP, $1996 b$ ) en el área metropolitana de San Salvador, cerca del 7 por ciento de los adultos declaró poseer un arma de fuego, esto significa que alrededor de 58,000 personas estarían armadas en el Gran San Salvador; la mayor parte por razones de "protección". Sin embargo, según fuentes policiales, un porcentaje significalivo de armamento estaría en manos de menores de edad y, por lo tanto, es muy probable que haya un número mayor de población armada.

La existencia de este armamento bélico ha tenido un impacto en la caracterización de la violencia salvadoreña. Buena parte de los delitos y las agresiones es llevada a cabo con artefactos explosivos y con armas largas: algunos asaltos en contra de camiones blindados han sido perpetrados usando bazucas; en una modalidad de enfrentamiento entre las pandillas se utilizan granadas de mano $y$ en repetidas ocasiones, sobre todo en los inicios de la nueva policía, las autoridades han externado su preocupación porque sus efectivos deben enfrentar delincuentes más y mejor armados que los mismos policías.

Resumiendo, las secuelas del conflicto bélico han sido factores contribuyentes al incremento $y$ mantenimiento de la violencia salvadoreña. La exacerbación de la ya existente cultura de violencia, la fragilidad de los aparatos encargados de la justicia y la seguridad pública y la gran circulación de armas en manos de la población han sido, en buena medida, producto de la particular historia reciente de conflicto y de paz sin previsión que ha enfrentado este país centroamericano. La verdad es que, según las evidencias recogidas sobre el pasado período antes del conflicto, los salvadoreños ya tenían un problema serio de violencia; en tal sentido la problemática no es nueva y no fue creada por la guerra, pero ésta contribuyó enormemente a que la violencia se institucionalizara en el sistema de valores y normas que rigen el comportamiento social de forma tácita en las interacciones personales. Cuando la violencia dejó de tener un sentido en el orden sociopolítico, se reforzó el espacio para la misma en las relaciones interpersonales. Esto, a su vez, fue posibilitado, por un lado, por el vacío institucional en materia de seguridad pública y de justicia: luego de la guerra, la sociedad salvadoreña carecía de mecanismos eficientes de control social que asegurasen la persecución del delito y el combate a la impunidad; $y$, por otro, a causa de la existencia de grandes cantidades de armamento que quedaron en manos de civiles en la posguerra.

Sin embargo, a todo lo anterior habría que agregar otro elemento particular del contexto salvadoreño y que, de alguna manera, puede añadirse como un factor importante en la dinámica de la violen- 
cia. Los acuẹrdos de paz no sólo terminaron con el conflicto armado, sino que además fueron planteados como un mecanismo para la construcción de una nueva sociedad; frente a esto, muchos salvadoreños crearon expectativas muy grandes con respecto al futuro nacional, sobre todo en el orden socioeconómico. Sin embargo, pasada la alegría del logro de paz, los salvadoreños empezaron a acusar un elevado nivel de frustración por la falta de resolución de sus viejos problemas y, sobre todo, por la permanencia de un modelo de exclusión social y económica. Los tratados de paz resolvieron el problema de la marginación política, pero al final no fueron capaces de resolver los problemas de exclusión socioeconómica. El Estado salvadoreño se vio limitado en su capacidad de integrar a todos los sectores en el rumbo del desarrollo y la atención. La existencia y dinámica de las pandillas juveniles en El Salvador, tanto como otros fenómenos del orden delincuencial, sugieren la necesidad de algunos sectores poblacionales de recuperar un espacio social perdido a través de la violencia. Una investigación elaborada por el Instituto Universitario de Opinión Pública (1997) mostró que la mayoría de los jóvenes que se integra a las pandillas juveniles, en la actualidad, reclama un poco de atención por parte de la sociedad, de la cual se siente profundamente marginado. Al final, la violencia sería un mecanismo legitimado y justificado por cierta parte de la población para recuperar un poder perdido sobre su entorno más inmediato.

\section{La expresión de la violencia en El Salvador}

\subsection{Las circunstancias}

¿Cómo se expresa la violencia en El Salvador en la actualidad? Buena parte parece estar relacionada con la delincuencia común. Según un recuento de noticias sobre violencia aparecidas en la prensa nacional escrita durante 1996, la causa identificada más común de homicidios es la delincuencia común, con un 26.1 por ciento de asesinatos en tales circunstancias. En cambio, el 12.4 por ciento de las muertes intencionales se deben a problemas de convivencia interpersonal: venganzas personales y asesinatos de familiares. Los jóvenes pandilleros asesinados representan también un porcentaje importante sobre el total de homicidios; según el recuento, el 8 por ciento de los homicidios se dio en un riña callejera entre "maras" (pandillas). Sin embargo, la mayor parte de los asesinatos, el 42.3 por ciento, ocurre en circunstancias no especificadas por la prensa. Estos hechos pudieron haber sido cometidos bajo distintas condiciones, pero el dato en sí mismo muestra la falta de control que tiene la sociedad sobre la ocurrencia de los hechos violentos.

De acuerdo con los registros del Instituto de Medicina Legal, las armas de fuego constituyen la primera causa de homicidio en el área metropolitana de San Salvador. Según los datos, el 48.6 por ciento de las muertes intencionales ha sido cometido con un arma de fuego; mientras que cerca del 20 por ciento es efectuado por medio de golpes y traumatismos en diversas partes del cuerpo de las víctimas; el 16.5 por ciento és cometido con arma blanca y el 7.3 por ciento muere por ahorcamiento. El resto muere a causa de artefactos explosivos y por causas indeterminadas. Sin embargo, el alcance letal del hecho varía en función del instrumento utilizado para causar la muerte; de acuerdo con el recuento de noticias de la prensa escrita, en el 44 por ciento de los casos de artefacto explosivo murió más de una persona en un sólo hecho; esto en contraposición con las muertes debidas a golpes, en las cuales sólo hay un fallecido en el $\mathbf{9 2}$ por ciento de los casos. Estos datos ayudan a acercarse también a la caracterización de la violencia. La disponibilidad de las armas de fuego posibilita casi la mitad de los asesinatos, usualmente cometidos en circunstancias delincuenciales. Además, el uso de armas de fuego y artefactos explosivos sugiere un tipo de violencia más impersonal que la provocada por armas blancas y golpes, donde la interacción personal es mayor.

Así, el elevado nivel de muertes por golpes sugiere la magnitud de muertes en riñas y peleas, lo cual tendría que ver con problemas de convivencia ciudadana; en otras palabras, la violencia que provoca muertes no sólo puede ser atribuida a la ola delincuencial que azota a El Salvador en la actualidad, buena parte de la misma ocurre en los ámbitos de coexistencia ciudadana y es ejecutada por personas que no son los clásicos criminales. Algo de esto señalan los resultados de la encuesta de victimización realizada para este estudio: del total de personas que declararon haber sido agredidas sin motivación de robo, el 62 por ciento conocía a su agresor.

\subsection{Los agresores}

No existen registros sobre los victimarios de los homicidios en El Salvador. Sin embargo, el 
estudio llevado a cabo por la Dirección de Política Criminal reveló que el 60 por ciento de los reclusos del sistema penitenciario salvadoreño posee menos de 30 años de edad. Según declaraciones de funcionarios policiales, cerca de la mitad de los hechores de los delitos contra el patrimonio son menores de edad. El estudio en el sistema penitenciario reveló también que el 45 por ciento de los encarcelados no ha estudiado más allá del sexto grado de primaria, mientras que un 32 por cięnto ha estudiado tercer ciclo (de séptimo a noveno grado). Por otro lado, el reporte revela que, en su mayoría, las personas que se encuentran en el sistema penitenciario son campesinos y obreros (Dirección General de Política Criminal, 1996).

\subsection{Las víctimas de la violencia}

Paradójicamente, las víctimas más frecuentes de la violencia homicida forman parte del mismo grupo demográfico que los agresores. Según las distintas fuentes y registros de homicidios, entre el 70 y el 85 por ciento de los fallecidos pertenece al sexo masculino y más de la mitad se encontraba entre los 15 y los 30 años al momento del hecho. La Figura 1, obtenida de los registros forenses de homicidios del AMSS, muestra que en el grupo de los hombres se alza el número de fallecidos por violencia hacia los 16 años, este número se mantiene alto hasta los 30 años cuando comienza a bajar; en cambio, en el grupo de las mujeres la incidencia de las muertes por homicidios se mantiene baja y sin mayores variaciones significativas.

Figura 1

Sexo y edad de las víctimas de homicidio según registros de Medicina Legal del AMSS

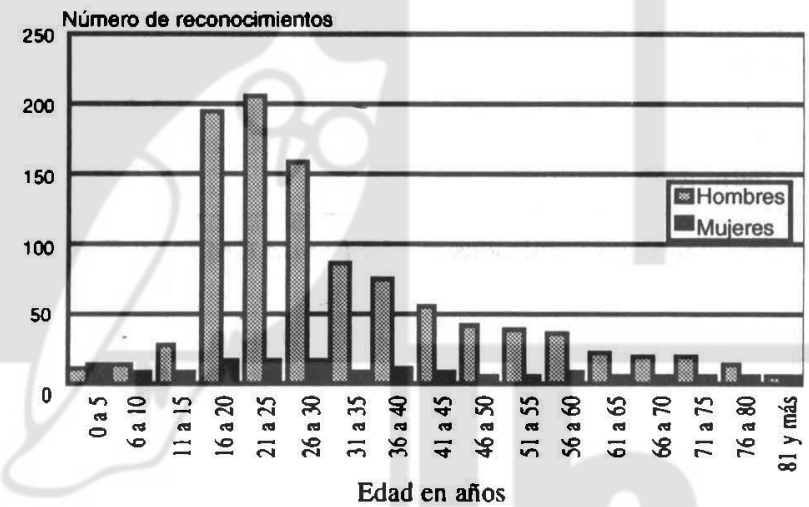

Fuente: base de datos de los registros del Instituto de Medicina Legal.

Lo anterior quiere decir que un hombre joven en El Salvador posee una de las probabilidades más altas en todo el mundo de morir asesinado. Así, éste constituye el grupo de mayor riesgo, diez veces más que en el grupo de las mujeres.

Ahora bien, en el ámbito de la delincuencia común no parecen existir diferencias importantes en el sexo y la edad de las víctimas. De acuerdo con el Estudio ACTIVA (IUDOP, 1996 $b$ ), tanto mujeres como hombres han sido víctimas de robos a mano armada en una proporción muy parecida; mientras que, en términos de edad, hacia los 21 años se da la mayor incidencia de asaltos, pero estos no llegan a tener una proporción significativamente mayor que la del resto de edades como en el caso de los homicidios. Adonde sí parece haber una diferencia importante en las víctimas de los asaltos es en el nivel educativo de los mismos; según los resultados, tres de cada diez personas con estudios de secundaria incompleta fueron asaltadas en el transcurso de un año, mientras que una de cada diez personas analfabetas ha 
sido robada en el mismo período; en el resto de niveles educativos las personas han sido víctimas en un 20 por ciento aproximadamente.

Lo anterior sugiere que la violencia homicida posee un carácter singular. Las muertes no vendrían entonces directamente como resultado de la acción delincuencial, aunque sin duda ésta contribuye, sino que en ellas estarían actuando otros factores relacionados con problemas de convivencia social como por ejemplo, el fenómeno de las pandillas juveniles en El Salvador', los traumas psicológicos por la guerra en excombatientes y población civil ${ }^{10}$, etc.

\subsection{El entorno de la violencia}

El recuento de noticias sobre la violencia llevado en 1996 muestra que la mayor parte de asesinatos informados por la prensa ocurrió en la vivienda o la vía pública. Un tercio de los fallecidos murió en la vía pública urbana; mientras que el 25.6 por ciento falleció en una casa de habitación; el 13.5 por ciento ocurrió en la zona rural y el resto de defunciones sucedió en otros sitios: la carretera, establecimiento laboral, etc. (ver Cuadro 1).

\section{Cuadro 1}

Fallecidos según lugar donde ocurrió el hecho

\begin{tabular}{lr}
\hline Lugar & $\%$ \\
\hline Vía pública urbana (calle, colonia) & 33.7 \\
Vivienda & 25.6 \\
Zona rural (barrancos, cañales, etc.) & 13.6 \\
Establecimiento laboral & 7.6 \\
Carretera & 6.3 \\
Autobús & 3.8 \\
Hospital & 1.6 \\
No se menciona & 6.0 \\
\hline
\end{tabular}

Fuente: base de datos de noticias publicadas por La Prensa Gráfica y El Diario de Hoy, 1996.

Ahora bien, con los datos del Instituto de Medicina Legal de 1996 se construyó un mapa sobre las regiones donde ocurren homicidios más frecuentemente en el área metropolitana de San Salvador. Dado que no son zonas geográficas del mismo tamaño y muchas incorporan municipios muy grandes, se optó por relativizar los números en función del número de habitantes que vive en cada zona según las proyecciones poblacionales y obtener tasas brutas de homicidios para cada zona de la ciudad". Los resultados muestran que no todo el AMSS es igualmente violento; existen

9. Un interesante ensayo fotográfico de la fotoperiodista Donna DeCesare sobre las pandillas en El Salvador plantea que éstas son el producto de la migración salvadoreña hacia ciudades como Los Ángeles en Estados Unidos, en los años de la guerra. Paradojicamente, los salvadoreños huían de la guerra en su pars, pero al llegar a Estados Unidos encontraron "la guerra de las calles" protagonizada por las pandillas a las que tuvieron que integrarse. La deportación de estos jóvenes importó algunas de las características del fenómeno pandillero en El Salvador.

10. Una de las masacres más fatales ocurridas en El Salvador en 1996 fue protagonizada por un artesano de un pequeño pueblo del norte del pars, quien por desavenencias con sus vecinos los atacó con granada y armas de fuego provocando la muerte de nueve personas y lesiones en diecisiete personas más (ver EDH, 31 de enero de 1996).

11. Dado el subregistro de los datos del Instituto de Medicina, este ejercicio no busca establecer las tasas regionales por sí mismas; más bien se hace sólo para comparar el nivel de violencia entre las distintas regiones de la ciudad. 
áreas donde ocurre una ingente cantidad de homicidios que colindan directamente con otras donde las muertes violentas son muy escasas (ver Figura 3.2). Esta zonificación de la violencia sugiere la intervención de varias variables, marginalidad, vigilancia, movimiento comercial, etc.

Por ejemplo, las regiones donde ocurren más homicidios son esencialmente dos: el área del llamado "centro de San Salvador" (zona 1) y la zona 14.2 al sur de la ciudad. La zona 1 se caracteriza por ser el centro comercial y antiguo de la ciudad; en él converge la mayor parte del tráfico de transporte público, se concentra la mayor cantidad de establecimientos comerciales y se encuentra un buen número de plazas y parques. Esto la convierte en la zona de mayor tránsito de personas y el área con la más grande densidad de personas no residentes. Esto contribuye a un fenómeno de confluencia que genera un desorden urbano mayúsculo, posibilita los hechos delincuenciales y crea una atmósfera de impersonalidad en medio de una gran cantidad de personas. La zona 1 parece formar un corredor de violencia hacia el oeste con las zonas 2 y 11 que se debilita en la medida en que se aleja del centro. Estas zonas, antiguamente lugar de asentamiento de colonias de clase alta y media-alta, constituyen ahora sectores de intensa actividad comercial y de mucho tránsito de personas. Sin embargo, la zonas justo al norte de éstas son sectores con un nivel muy bajo de homicidios; estas zonas, en buena parte residenciales, aún se constituyen en barrios y colonias de sectores medios que no denotan los mismos niveles de actividad urbana que las zonas al sur.

En cambio, la zona 14.2, otra de la zonas más violentas, constituye uno de los sectores periféricos de la ciudad con un elevado nivel de pobreza y marginalidad; en esta área se encuentra uno de los asentamientos marginales más grandes de la ciudad y considerados de mayor peligrosidad de la urbe. Este asentamiento, a diferencia de otros igualmente extensos, carece de establecimientos que tengan vigilancia y no colinda con cuarteles del ejército. Esta zona colinda al oriente con otra que muestra un nivel no tan alto, pero sí significativo de muertes por homicidio; esta zona está compuesta también por asentamientos marginales pero además posee barrios y colonias de sectores medio-bajos y obreros. Al oeste de esta zona se encuentra una de las áreas residenciales para clases medias y altas de reciente crecimiento y ésta, por el contrario, registra un nivel de muertes por homicidios totalmente opuestos.

Este rápido análisis de la distribución geográfica de la violencia homicida sugiere que la misma aparece asociada a áreas de dinámica actividad comercial y a populosos sectores marginales. Estos factores no pueden ser identificados como exclusivamente determinantes de la violencia urbana en el AMSS, pero su presencia estaría indicando la importancia de los mismos en la configuración del riesgo. Desde esta situación, lo más razonable es pensar que estos elementos, conjugados con otros, invisibles al examen geográfico, constituyen algunos de los condicionantes de la violencia.

\section{Conclusión}

La presente investigación encontró que los factores sociales que explican la configuración de buena parte de la violencia en El Salvador en la década de los noventa se originaron en la historia reciente de guerra y paz. El conflicto bélico dejó una serie de secuelas que convirtieron a la sociedad salvadoreña en un terreno fértil para el desarrollo de la problemática. En otras palabras, a inicios del presente decenio, este país centroamericano llegó a reunir la mayor parte de elementos que los estudiosos han señalado como factores de riesgo asociados a la violencia. Sin embargo, a diferencia de la década pasada, el actual es un fenómeno más bien difuso y, probablemente, más generalizado. La prolongada e intensa confrontación armada salvadoreña exacerbó la ya existente y centenaria cultura de violencia social, afectó los aparatos de justicia y seguridad y dejó circulando una ingente cantidad de armamento.

En buena medida, lo que sucede en la actualidad es el producto del deterioro de la convivencia social, de la militarización de la conciencia pública y de la educación de generaciones en la agresión como forma de resolver diferencias; aspectos que sobrevivieron al fin de la guerra para mostrar sus efectos en una cultura de violencia posbélica. Pero no sólo eso, la particular manera de finalizar la guerra comprometió a los incipientes aparatos de justicia y seguridad, de por sí históricamente incompetentes, y debilitó el potencial de la sociedad para mantener el orden de justicia y legalidad necesarios para la reconstrucción. La tarea de seguridad pública fue asumida por una institución principiante que en un inicio no disponía de todos 


\section{Figura 2}

\section{Distribución de las tasas de homicidio en el AMSS}

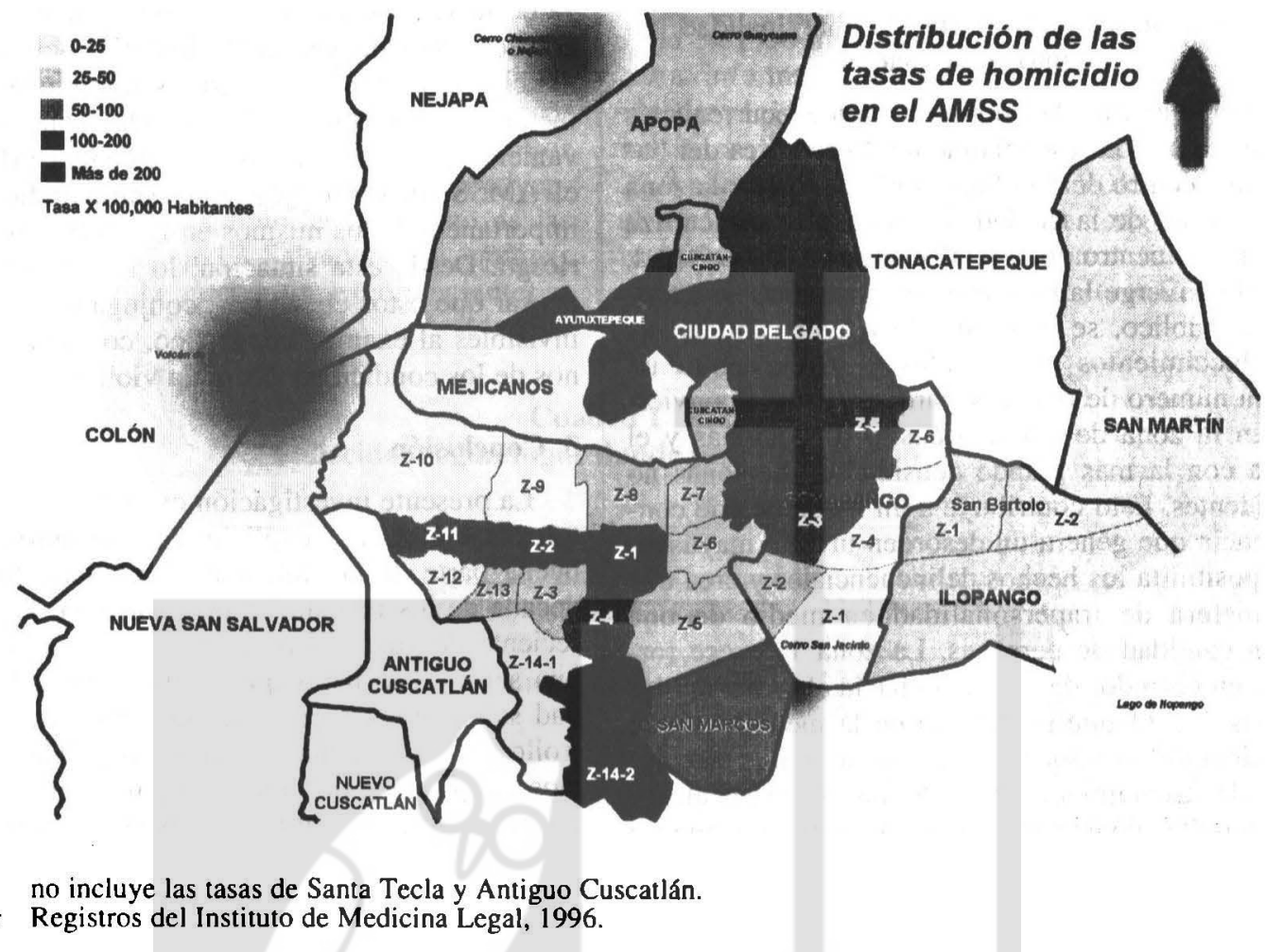

Fuente: Registros del Instituto de Medicina Legal, 1996.

los recursos técnicos y políticos para desarrollar eficientemente su labor. El aparato de justicia inició la era de paz sin haber corregido y depurado completamente la corrupción y la ineficiencia formadas en los años de la guerra. Finalmente, la ola de violencia de los noventa ha sido posibilitada también por la enorme disponibilidad de armamento circulante como producto de la guerra.

Por otra parte, el estudio mostró que la violencia, a pesar de su magnitud, no afecta de la misma manera a toda la población. Los diferentes registros muestran que los hombres entre 15 y 30 años de edad son las víctimas más frecuentes del fenómeno. En El Salvador, un hombre tiene ocho veces más probabilidad de morir violentamente que una mujer, y un joven de 16 años tiene cuatro veces más probabilidad de morir a causa de la violencia que un hombre de 50 años.

Con todo y dadas las condiciones de información en El Salvador, éste constituye un primer acercamiento al fenómeno de la violencia. En realidad quedan muchas preguntas sin resolver y muchas cuestiones que aclarar. Por el momento, parece clara la dimensión del problema en el caso salvadoreño y más clara aún la necesidad de estudiarlo profundamente y atenderlo de inmediato. En tal sentido, los desafíos parecen obvios.

En primer lugar, en el caso salvadoreño es necesario construir un sistema eficiente de recolección de información sobre la violencia. Ello implica la depuración de los registros existentes, la creación de unidades de recopilación y la destinación de ingentes recursos para ese fin. El Salvador, por su tamaño y el desarrollo de las comunicaciones, posee las condiciones para construir un sistema de amplia cobertura nacional que pueda centralizar y gestionar la información necesaria para la toma de decisiones. En segundo lugar, la dimensión de la problemática no permite más dilaciones en la atención del problema; ante todo, es fundamental comenzar a actuar sobre los factores 
asociados a la violencia y que en el caso salvadoreño se han presentado tan agudamente. En tal sentido, las campañas de recolección y control de armas deberían ser un punto esencial en la agenda del Estado; muy poco se puede hacer en la prevención de la violencia si se sigue disponiendo de los instrumentos para agredir. También debe prestarse atención especial a la profesionalización de los aparatos de justicia y seguridad como una forma de erradicar de una vez por todas la impunidad. La profesionalización no pasa sólo por la adquisición de mayores recursos técnicos para hacer frente al crimen, pasa también por la formación de una institucionalidad basada en la justicia y la ética que haga frente a la corrupción y a la negligencia. Finalmente y de manera más estructural, es necesario enfrentar el problema de la salud psicosocial de la población para erradicar la cultura de la violencia; esto implica un esfuerzo significativo en términos de educación tanto dentro de la familia como en la escuela. Las nuevas generaciones deben ser entrenadas en tal forma que la resolución de conflictos no impliquen violencia o agresión; ello pasa necesariamente por una revisión de los sistemas de valores vigentes en la actualidad para reeducar en otros que privilegien la solidaridad y el respeto mutuo. El problema de la salud psicosocial y la educación en la no violencia ha sido uno de los tópicos menos abordados después del fin de la guerra probablemente por el temor a remover la memoria del pasado. Más que de resucitar el conflicto se trata de que los salvadoreños aprendan del pasado para reconstruir sus relaciones de convivencia para el futuro; se trata de que la paz sea asumida como parte del desarrollo psicosocial, no sólo como parte de un acuerdo político. $\mathrm{Y}$ es que una cultura de paz sólo puede lograrse haciendo frente a la cultura de la violencia.

\section{Referencias}

Alvarenga, P. Cultura y ética de la violencia. El Salvador 1880-1932, Editorial Universitaria Centroamericana, 1996.

Anderson, T.R. El Salvador 1932. Los sucesos políticos, Ciudad Universitaria Rodrigo Facio, Editorial Universitaria Centroamericana, 1976.

Cardenal, R. Manual de historia de Centroamérica, UCA-Editores, 1996.

Corado, $H$. "The demobilization processes of the salvadoran armed forces". En: F. J. Aguilar (edit.). Demobilization, demilitarization and democratization in Central America, Fundación Arias para la Paz y el Progreso Humano, 1994.
Dirección General de Política Criminal. Estudio acerca de la capacidad del sistema penitenciario en El Salvador: abordaje estadístico descriptivo, El Salvador, Ministerio de Justicia, 1996.

Estudios Centroamericanos (ECA)."Violencia institucionalizada", No 549, 1994, pp. 615-28.

García, J. "Reportan 29 personas masacradas", El Diario de Hoy, San Salvador, 9 de enero de 1996.

Guerrero, R. "Prevención de la violencia a través de] control de los factores de riesgo", trabajo presentado en la reunión El desafio de la violencia criminal urbana, Río de Janeiro, Brasil, Documento mimeografiado, 1997.

Hernández, A. "Violencia avanza incontrolable", La Prensa Gráfica, San Salvador, 11 de enero de 1996.

Instituto Universitario de Opinión Pública. "Solidaridad y violencia. Los jóvenes pandilleros en el gran San Salvador", Estudios Centroamericanos (ECA), No 585-586, 1997, pp. 695-710.

Instituto Universitario de Opinión Pública. Sondeo sobre violencia en los centros educativos del área de San Salvador, Serie de informes 59, $1996 a$.

Instituto Universitario de Opinión Pública. "Las actitudes de los salvadoreños en torno a las leyes", Estudios Centroamericanos (ECA), No 576, 1996b, pp. 905-920.

Instituto Universitario de Opinión Pública. Encuesta sobre la juventud salvadoreña organizada en pandillas, Serie de informes IP, 1996c.

Instituto Universitario de Opinión Pública. Encuesta sobre el primer año de gobierno de Armando Calde. rón Sol, Serie de informes 48, 1995.

Instituto Universitario de Opinión Pública. "La delincuencia urbana. Encuesta exploratoria". Estudios Centroamericanos (ECA), No 534-535, 1993, pp. 472-479.

Instituto Universitario de Opinión Pública. "La violencia en El Salvador". Estudios Centroamericanos (ECA), No 569, 1996a, pp. 240-249.

Instituto Universitario de Opinión Pública. "Actitudes y normas culturales sobre la violencia en el área metropolitana de San Salvador (ACTIVA)", Informe provisional, $1996 b$.

Martín-Baró, I. Acción e ideología. Psicología social desde Centroamérica, UCA-Editores, 1996.

Martín-Bar6, I. "Guerra y salud mental", Revista de Psicología de El Salvador, 9(35):71-88, 1990.

Martín-Baró, I. "La violencia en Centroamérica: una visión psicosocial", Revista de Psicología de El Salvador, 9(35), 123-146, 1990.

Martín-Baró, 1. "La violencia política y la guerra como causas del trauma psicosocial de El Salvador", $R \boldsymbol{e}$ vista de Psicología de El Salvador, 7(28): 123-141, 1988.

Naciones Unidas. "Informe del Secretario General sobre la Misión de Observadores de las Naciones Unidas en El Salvador. 24 de marzo de 1995". En Ejecución de los Acuerdos de paz en El Salvador, recalendarizaciones, acuerdos complementarios y otros 
documentos importantes, Nueva York, Unidad de apoyo al enviado del Secretario General en El Salvador, 1997.

Naciones Unidas. "Informe del Secretario General sobre el fin del enfrentamiento armado en El Salvador". En Las Naciones Unidas y El Salvador 1990-1995. Nueva York, Departamento de Información Pública, $1995 a$.

Naciones Unidas. "Carta de fecha 8 de enero de 1993 dirigida al Presidente del Consejo de Seguridad por el Secretario General, relativa al descubrimiento de un depósito clandestino de armas del FMLN". En Las Naciones Unidas y El Salvador 1990-1995. Nueva York, Departamento de Información Pública, 1995b. Naciones Unidas. "Informe de la División de Derechos Humanos de la ONUSAL correspondiente al período comprendido entre el $1^{\circ}$ de enero y el 30 de abril de 1993 (Extracto)". En Las Naciones Unidas y El Salvador 1990-1995. Nueva York, Departamento de Información Pública, 1995c.

Organización Panamericana de la Salud. Las condiciones de salud en las Américas, volumen I, Washington, 1994.

Popkin, M.; Spence, J. y Vickers, G. Justice Delayed. The slow pace of judicial reform un El Salvador. Washington, 1994.

Samayoa, J. "Guerra y deshumanización: una perspectiva psicosocial", Estudios Centroamericanos (ECA), No 461, 1986, pp. 213-225.

Spence, J.; Dye, D., Lanchin, M. et al. Chapultepec: cinco años después. La realidad política salvadoreña y un futuro incierto. Cambridge. Hemisphere Initiatives, 1997.

White, A. El Salvador, UCA Editores, 1983. 